\title{
Monarquía y medios de comunicación: de la Transición a Corinna zu Sayn- Wittgenstein ${ }^{1}$
}

\section{Monarchy and media: from the Spanish transition to democracy to Corinna zu Sayn-Wittgenstein}

\author{
Ana María Velasco Molpeceres*
}

*Facultad de Filosofía y Letras, Universidad de Valladolid, España

\section{Resumen}

\begin{abstract}
El fin de este texto es el estudio de la relación entre los medios de comunicación y la monarquía española. Este trabajo se centra en la publicación Vanity Fair España y los reportajes sobre la relación de Juan Carlos I y Corinna zu Sayn-Wittgenstein. Los objetivos son identificar la línea editorial de VFsobre la Casa Real e investigar en los conflictos entre periodismo y democracia en España (la censura y la autocensura). La hipótesis principal de este artículo es que la inviolabilidad que rodeaba a la corona desde la Transición ha ido desapareciendo. En ese nuevo escenario mediático, situamos los reportajes sobre el rey y su amiga que publicó VF en los números 46 y 56 (estudiados a través del Análisis Textual), tras el accidente en Botswana en abril de 2012.
\end{abstract}

Palabras clave: Vanity Fair, Monarquía española, Corinna zu Sayn-Wittgenstein, Juan Carlos I, Prensa española, Transición española

Abstract

The aim of this text is the study of the relationship between the media and the Spanish monarchy. This work focuses on the Spanish publication Vanity Fair and the reports covering the relationship between Juan Carlos I and Corinna zu Sayn-Wittgenstein. The objectives are to identify the editorial line of $V F$ about the Royal House and to investigate the conflicts between journalism and democracy in Spain (censorship and self-censorship). The main hypothesis of this article is that the inviolability that surrounded the crown since the Transition has been disappearing. In this new media scenario, we situate the reports about the king and his friend who published VF in numbers 46 and 56 (studied through Textual Analysis), after the accident in Botswana in April 2012.

Keywords: Vanity Fair, Spanish monarchy, Corinna zu Sayn-Wittgenstein, Juan Carlos I, Spanish press, Spanish transition to democracy

\section{Introducción}

El objetivo de este texto es el estudio de la relación entre los medios de comunicación y la monarquía española. En concreto, a través del análisis de las investigaciones sobre Corinna zu Sayn-Wittgenstein que la revista Vanity Fair España le dedicó para averiguar quién era y qué tipo de relación tenía con el rey Juan Carlos I. Este trabajo pretende identificar la línea editorial de la publicación respecto a la Casa Real y a la institución monárquica, así como ahondar en los conflictos entre periodismo y democracia. También quiere acercarse a la imagen transmitida sobre los protagonistas de la polémica ocurrida en abril de 2012, cuando

\footnotetext{
${ }^{1}$ Este artículo es parte de los trabajos de los proyectos "Perfiles del centro político (1976-1986): proyectos y realizaciones", referencia HAR 2016-75600-C2-2-P (AEI/FEDER, UE) y "Hacer las Europas: identidades, europeización, proyección exterior y relato nacional español en el proceso de integración europea" [HAR2015-64429-C2-2-P (MINECO/FEDER)]. El mismo también ha sido posible gracias a una ayuda FPU del Ministerio de Educación, Cultura y Deporte de España.
} 
el rey se rompió una cadera mientras cazaba en Botswana, en compañía de la alemana, y tuvo que regresar a España para ser operado.

Para ello, nuestro objeto de análisis serán los números 46 y 56, publicados en junio de 2012 y en abril de 2013, que están dedicados a la princesa. El primero supuso la publicación en nuestro país de una investigación completa sobre zu Sayn-Wittgenstein, cuya aparición en los medios de comunicación hizo que surgiese una gran polémica al saberse que estaba con el rey cuando sufrió el accidente. De hecho, tras la operación, el monarca compareció ante las cámaras para pedir perdón por su comportamiento.

El principal objetivo de este trabajo es, como hemos dicho, estudiar el tratamiento que Vanity Fair dio a la monarquía, a don Juan Carlos y a Corinna zu Sayn-Wittgenstein en su investigación. La princesa fue la protagonista del número 46, que apareció en los quioscos semanas después del accidente del rey. Fue una exclusiva importante, de corte poco halagador, en un momento crítico para la Casa Real por lo que hemos considerado que su estudio es importante. Casi un año más tarde la revista le dedicó otro reportaje en el número 56. La diferencia entre ambos era grande: pasó de ocupar la portada a ir en páginas interiores pese a que su número había sido el más vendido y, entre otras cuestiones, VFvio cómo fue posible contactar con zu Sayn-Wittgenstein. Por todo esto hemos decidido profundizar en esos reportajes, que se complementan con la publicación a finales de 2013 de un libro que conmemoraba el quinto aniversario de la misma y daba detalles sobre ellos.

La hipótesis de este trabajo es que la Corona ha gozado del favor y del silencio de los medios desde la Transición, especialmente desde el intento fallido de golpe de estado de 1981 (finalizado con la intervención televisada del rey en apoyo de la Constitución), pero que con el tiempo el aura simbólica y el mito de don Juan Carlos se han ido resintiendo. La aparición pública de zu Sayn-Wittgenstein en los medios creemos que es un ejemplo de ello. Por tanto, pretendemos investigar sobre la imagen publicada de la monarquía y acerca del tratamiento de la misma en el medio que profundizó en primer lugar en España sobre la princesa alemana.

En definitiva, los objetivos de este texto son:

- Estudiar la imagen transmitida de la monarquía española por la revista.

- Analizar los conceptos difundidos de Juan Carlos I y de Corinna zu Sayn-Wittgenstein.

- Profundizar en el tratamiento fotográfico de los reportajes y en los mensajes transmitidos por las imágenes.

- Indagar en las diferencias entre los números 46 y 56 de Vanity Fair respecto de los protagonistas de la información y la monarquía española.

\section{Metodología}

Para alcanzar los objetivos planteados, esta investigación ha sido realizada aplicando la Teoría del Texto o Análisis Textual; desarrollada por Jesús González Requena (1996), catedrático de Comunicación Audiovisual de la Universidad Complutense de Madrid, que viene trabajando desde el pasado siglo en este método. Su teoría parte del giro lingüístico, como lo definió Richard Rorty (1990), que considera que el lenguaje prima sobre la noción de realidad, pues no hay pensamiento fuera de lo lingüístico. 
Así, el objeto de estudio ya no es la realidad sino el símbolo: el texto -que es tanto lo gráfico, de grafía, como la imagen-; y lo real desaparece bajo la máscara que lo expone, que es el vehículo no inocente de un engaño. No hay verdades y mentiras, se trata de expresiones. El lenguaje sirve para manipular y, además, cada receptor lo interpreta de una manera. Es por esto que consideramos especialmente interesante este método de investigación para el estudio de los mensajes periodísticos. Los medios no son exclusivamente transmisores de los acontecimientos sino agentes históricos y sociales, que buscan convencer a sus receptores de posiciones ideológicas que estén de acuerdo con sus intereses. No se trata únicamente de que tergiversen o mientan, sino de que siendo veraces y atendiendo a la ética y a unas líneas editoriales más o menos explícitas, pueden construir sobre un mismo hecho o un personaje un discurso completamente diferente.

Estudiar, por tanto, qué transmiten los medios y cómo (la forma estética, las imágenes escogidas, la ubicación de los mensajes, el contenido de la redacción, las fuentes consultadas, la extensión, etc.) es fundamental para comprender qué punto de vista hacen público, así como para acercarnos a los intereses que hacen que las distintas informaciones salgan a la luz. La teoría de González Requena se vincula, pues, al lenguaje constructor de la realidad (y de sus mentiras). El Análisis Textual consiste en el deletreo del texto objeto de estudio, narrando la información que llega al receptor. En nuestro caso concreto, vamos a aplicar este método, como hemos dicho, a los números 46 y 56 de Vanity Fair, edición española, publicados en junio de 2012 y abril de 2013.

No obstante, aunque el objeto de estudio de este texto son esos dos números, hemos considerado necesario acercarnos a más ejemplares para dar el contexto adecuado y comprender la relación entre la revista y la monarquía. Por ello se han analizado los primeros 104 números de la cabecera, que corresponden a los dirigidos por Lourdes Garzón, antes de ser sustituida por Alberto Moreno.

\section{La monarquía española y los medios de comunicación}

Profundizar en la imagen de la monarquía en España es una cuestión compleja. Por un lado, desde comienzos del siglo XX, el descontento con reyes como Alfonso XIII era patente; pero, además, el franquismo mantuvo una ambivalente posición respecto a la monarquía. La llegada de la democracia supuso el fin de la censura y del control de los medios de comunicación. Sin embargo, se protegió especialmente a la corona y al soberano. El rey, que supuestamente solo tiene dimensión simbólica en el Estado, será un personaje clave en la Transición. Esto le da un aura de prestigio, que se acrecienta tras el 23F, y el periodismo sella "un pacto no escrito con la Monarquía [...] a todos les vino bien, entonces y durante mucho tiempo, la figura moderadora del monarca y su capacidad de influencia en sectores sociales muy diversos" (López y Valera). Zugasti (2005 y 2007) o Fernández (2013) inciden igualmente en ese tabú.

Juan Carlos I pasa a comunicarse directamente con la ciudadanía a través de sus tradicionales discursos navideños de Televisión Española y las informaciones vinculadas a la Casa Real son transmitidas por los medios de forma consensuada con Zarzuela. Se sabe poco de la realeza y su inviolabilidad hace que se mantengan en secreto las cuestiones más inquietantes. Las otras informaciones o "no aparecían, o eran condenadas al ostracismo, a medios de comunicación menores, con escasa influencia, o de carácter irreverente" (López y Valera, 2013). E incluso cuando algún medio minoritario, y de tipo satírico, se aleja 
demasiado de la corrección establecida, la publicación se secuestra. Fue el caso de la revista El Jueves, en julio de 2007, por un supuesto delito de injurias a la Corona, al aparecer una caricatura de los príncipes de Asturias manteniendo relaciones sexuales.

Precisamente porque el humor gráfico fue casi el único espacio en que hasta hace poco se pudo criticar a la monarquía, esta línea de investigación ha sido la más fértil en estudios. Cabe destacar los trabajos de Carratalá (2015) sobre los medios digitales, Mogin-Martin (2006) respecto del Jueves o Domínguez y Mateu (2014) acerca del viaje de caza de elefantes de Juan Carlos I en 2012. Este incidente, que supuso la operación del rey de la cadera en España tras rompérsela, la salida a la luz de su acompañante y supuesta amante Corinna zu Sayn-Wittgenstein y la petición de perdón por parte del soberano, también ha generado literatura.

Herrero y Medina (2016) han estudiado cómo esa disculpa ha sido una estrategia de restauración de imagen de la monarquía española y del propio rey; Ramos (2013) se ha acercado al incidente de Botswana y el tratamiento del mismo por parte de los medios, Castro-Villacañas (2013) también ha investigado el fracaso de la monarquía y Widlak y Sorribes (2015) se han acercado a figuras secundarias del declive de la Casa Real como la reina Sofía y su imagen en los medios. Este declive, propiciado por escándalos como el de la supuesta corrupción del Caso Nóos, que afectaba a Iñaki Urdangarin y la infanta Cristina pero también a la Zarzuela; la aparición de Corinna zu Sayn-Wittgenstein como acompañante del rey y posible poder en la sombra del Gobierno de España; así como el cambio generacional y la mayor apertura informativa vinculada a los medios digitales han supuesto la llegada de una nueva relación entre los medios y Casa Real.

López y Valera (2013) han investigado la información sobre la monarquía española en Eldiario.es y Vozpopuli.com y también Ramos (2012) ha profundizado respecto de los escándalos de la corona española en la prensa digital y el futuro de la monarquía, estudiando cómo se ha pasado del silencio cómplice sembrado en la Transición al tratamiento exhaustivo los medios. Llama la atención que no haya trabajos sobre el papel de Vanity Fair España en ese camino crítico, sobre todo teniendo en cuenta que fue el primer medio nacional en llevar a zu Sayn-Wittgenstein en portada y hacer un reportaje sobre ella en junio de 2012, un mes y medio después de que su nombre saliera a la luz. Este estudio pretende llenar ese vacío e indagar precisamente en el tratamiento de $V F$ respecto de la monarquía en el nuevo panorama de crítica de la institución.

En 2009, De Pablos y Ardévol ya consideraban que el silencio crítico de la prensa española respecto de la monarquía se terminaba y marcaban un punto de inflexión en el año 2008. En aquel momento había ocurrido un pequeño incidente que alimentó el debate mediático: en noviembre de 2007, en la XVII Cumbre Iberoamericana, el rey le había espetado a Hugo Chávez que por qué no se callaba, ya que estaba interrumpiendo continuamente al presidente José Luis Rodríguez Zapatero. La cuestión de qué dimensión podían tener los actos del soberano, igual que en aquel lejano 23-F en que fue clave para desbaratar el golpe de estado, se ponía sobre la mesa y el aura mítica que rodeaba a la Corona se iba desvaneciendo.

No obstante, aún faltaban muchas cuestiones controvertidas. Pocos días después se hizo efectivo el divorcio de la infanta Elena y de Jaime de Marichalar, sobre quien se había rumoreado de su adicción a la cocaína en Época. La cuestión sobre los familiares de don Juan Carlos había arreciado en noviembre de 2003 cuando se informó del compromiso del príncipe con la periodista divorciada Letizia Ortiz y también se recordaron las anteriores parejas de don Felipe. Y en el 2004 se realizó la comentada compra de la casa de Pedralbes por los duques de Palma, que posteriormente se supo, había sido adquirida con dinero del Instituto Nóos y 
Aizoon, sociedad de los duques. En mayo de 2006, el rey reunió a sus hijos para recordarles la máxima: trabajo, no negocios. Un mes después, Urdangarin abandona su actividad en Nóos. Sus actividades, entre ellas las relacionadas con sus negocios y la mansión de Pedralbes que había comprado hacía unos años, saltaron a los diferentes medios, especialmente a El Mundo. La atención sobre los consortes reales va en aumento.

En paralelo, doña Sofía salta al punto de mira. La publicación del libro La reina muy de cerca (2008), escrito por Pilar Urbano tras entrevistar a la reina que actualizaban una biografía autorizada que había escrito en 1996, con algún revuelo, después de publicar José Luis de Vilallonga la suya sobre el monarca en 1993, generó enorme debate por las opiniones de doña Sofía. La Casa del Rey en un comunicado afirmó que las declaraciones eran privadas e inexactas pero los medios se hicieron eco de la controversia.

La polémica continuó tras el anuncio en 2009 del divorcio de los duques de Lugo y, en 2010, el juez José Castro, que instruía el Caso Palma Arena, abrió una pieza separada para investigar al Instituto Nóos y hay un clamor popular preguntándose por qué, en mayo, la reina no ha visitado al monarca tras extirpársele un nódulo pulmonar -lo que Pilar Eyre (2012) explica como un rechazo de doña Sofía a zu Sayn-Wittgenstein. La mala imagen de la Corona hace que aparezcan libros como el de Peñafiel (2011) titulado El rey no abdica o el de Urbano (2011) El precio del trono. Y en octubre de ese año, en medio de la crisis económica, la monarquía suspendió por primera vez (con un 4,89) en el barómetro del Centro de Investigaciones Sociológicas (CIS) ${ }^{2}$. En noviembre de 2010, el aprobado era raspado, un 5,35, pero pasaba el umbral.

Tras los registros de la Fiscalía Anticorrupción en los despachos de Nóos en Barcelona, Urdangarin el 11 de noviembre de 2011 emite un comunicado en el que afirma que va a defender su honorabilidad e inocencia y un mes después publica otro en el que lamenta los daños que está causando a la Casa Real, que nada tenía que ver con sus actividades privadas. El 29 de diciembre de 2011, Urdangarin es imputado por el juez Castro, quien le cita a declarar para febrero de 2012. En el tradicional mensaje navideño de Juan Carlos I en TVE, este se desmarca de su yerno asegurando que la justicia es igual para todos. Sin embargo, el 11 de abril de 2012, el nieto mayor de los reyes se dispara en un pie por accidente mientras practicaba el tiro junto a su padre con una escopeta, prohibida para un menor de catorce años. El debate surge por el comportamiento de su progenitor, así como del joven, y empeora drásticamente tres días después. El rey se ha fracturado la cadera en un accidente mientras estaba cazando elefantes en Botswana y tiene que regresar a España a ser intervenido quirúrgicamente, por cuarta vez en los últimos veinticuatro meses.

Tras la operación, pide perdón por su comportamiento ante las cámaras y salta ante la opinión pública su acompañante zu Sayn-Wittgenstein. Por primera vez, más allá de los rumores y lo minoritario, la cuestión de las amantes del rey aparece en primera plana. Por otra parte, las voces que implican al soberano y a la infanta Cristina en la supuesta corrupción de Urdangarin son cada vez mayores. La imagen de la monarquía sigue cayendo y los medios se hacen eco. El pacto de silencio de la Transición sobre la monarquía y la vida privada del rey, así como la posible participación de la alemana en asuntos oficiales de España, salta a la primera plana. Al mes, VF publica un completo reportaje sobre la princesa. Por otra parte, las voces que señalan la implicación del monarca y la infanta Cristina en la supuesta corrupción de Urdangarin son cada

\footnotetext{
${ }^{2}$ El barómetro del CIS es una encuesta mensual (realizada a unas 2.500 personas), salvo en agosto, cuyo objetivo es medir el estado de la opinión pública española del momento. Incluye un bloque de preguntas fijas (sobre la situación económica y política, etc. y trimestralmente acerca de las actitudes políticas y la intención de voto) y otro variable, que se dedica a un tema de interés sociopolítico del momento. La pregunta sobre la monarquía ha sido realizada en diversas ocasiones y sus resultados han generado gran interés.
} 
vez mayores. La imagen de la monarquía sigue cayendo y los medios se hacen eco de la deriva de la Casa Real.

Las celebraciones por el setenta y cinco aniversario del rey intentan encaminar las relaciones con los medios y concede una entrevista, el 4 de enero de 2013, a Jesús Hermida, que se emite por TVE y dura una media hora. Desde que en 1992 Selina Scott le entrevistó para un documental que se emitió primero en Reino Unido y luego en España, donde se vio de forma negativa, el monarca no había vuelto a conceder una. Sin embargo, el tono de la misma es halagador y no toca ninguno de los conflictos que afectan a la institución. El 23 de febrero de 2013, Urdangarin hace su segunda declaración en los Juzgados de Palma, donde afirma que la Casa Real no autorizó las actividades de la Fundación Nóos; al contrario de lo que los correos de su exsocio, Diego Torres, afirmaban. En ellos también se mencionaba a zu Sayn Wittgenstein como parte de las operaciones.

Ese mismo mes, la alemana asegura en una entrevista que hacía trabajos confidenciales para el Gobierno español y el 19 de marzo el director del Centro Nacional de Inteligencia (CNI) comparece a puerta cerrada en el Congreso de los Diputados para explicarlo. El tres de abril, la infanta Cristina es imputada por el juez y Vanity Fair saca su segundo número sobre cómo y cuándo trabajó Corinna por el Rey y por España. En julio de 2013, aparecen publicados los emails sobre supuestas infidelidades de Urdangarin, escritos por él mismo. Aunque intenta frenar su difusión en prensa en los tribunales, la revista satírica Mongolia logra publicar los correos electrónicos.

El setenta y seis cumpleaños del rey no le deja buen sabor de boca. En la Pascua Militar se equivoca y parece fatigado. El siete de enero de 2014 el juez Castro, después de que la Fiscalía parara la imputación de la infanta Cristina, lo vuelve a hacer. Su vídeo declarando, posteriormente, se filtrará y su actitud será muy criticada. Anteriormente, en el cumpleaños de don Felipe, tres semanas después, su padre le anuncia que desea abdicar y que debe ser en primavera de ese año porque el 2015 tiene por delante cuatro procesos electorales que complicarían la composición del Parlamento.

El 23 de marzo de 2014, como cerrando una etapa, muere Adolfo Suárez en Madrid y tras el funeral el monarca se reúne con Mariano Rajoy en Zarzuela y le informa. A partir de ese momento hay reuniones del Gobierno para diseñar un marco jurídico para la abdicación, que se anuncia el dos de junio tras la multiplicación de los rumores. El 18 de ese mes el monarca sanciona la ley orgánica que hacía efectiva su abdicación y comienza el reinado de Felipe VI. La monarquía, con un nuevo cabeza, entra en una nueva fase de relación con los medios. Aún tiene pendientes diversos escándalos, no solo el del Caso Nóos (a propósito del cual, don Felipe decide revocar a su hermana el ducado de Palma), sino también el ininterrumpido revuelo asociado a Corinna zu Sayn-Wittgenstein.

Esta última, desde el mutismo inicial tras saltar a la palestra en abril de 2013, ha cambiado notablemente su relación con la prensa. Del silencio inicial pasa a contestar al retrato, de ambiciosa lobista que usa su belleza y su relación con el rey, que le hacen los medios. Le preocupa especialmente su vinculación con Iñaki Urdangarin y el Caso Nóos y así concede varias entrevistas. En primer lugar, a El Mundo en Mónaco, que se publicó en dos partes los días 24 y 25 de febrero de 2013 y el ocho de marzo protagonizó la portada de Hola en una exclusiva entrevista. En ese año además declara para el reportaje de Vanity Fair de abril y en octubre se conoce que es asesora de Alberto y Charlene de Mónaco. Hasta el día de hoy, cuando se ha revelado en junio de 2017 que un robo que sufrió en su residencia monegasca fue supuestamente 
perpetrado por el CNI con el objetivo de recuperar documentación confidencial que tenía vinculada a don Juan Carlos, sigue despertando gran interés mediático.

Como decíamos, el silencio de la Transición vinculado a la monarquía se ha roto. Sin embargo, hay pocos estudios que se acerquen a este proceso y menos aún, comprensiblemente dada la cercanía de los acontecimientos, a la nueva etapa de la monarquía bajo el reinado de Felipe VI. Sobre esto, Müller (2014) ha estudiado la relación entre Felipe VI y la nueva generación de españoles; Palacios (2015) ha investigado el paso del juancarlismo al siguiente rey o Sintes, Yeste y Franch (2016) han profundizado en la sucesión de Juan Carlos I por su hijo y el seguimiento de la misma en la prensa.

\section{La monarquía española: un tema clave para Vanity Fair}

Para VF España las monarquías y la nobleza van a ser un foco de continua atracción. No es de extrañar, pues el título de $L a$ feria de las vanidades es una metáfora de los contenidos de la publicación. La relación, por ejemplo, entre la línea editorial de $A B C$ y la exaltación de la Casa Real está ampliamente estudiada, aunque el posicionamiento de otras publicaciones sobre la monarquía ha sido tratado poco. El fin de este trabajo es contribuir a rellenar ese espacio en la investigación, con un estudio actual, referido a uno de los momentos más delicados en la vida del monarca: el de su accidente en Botswana, la aparición de zu SaynWittgenstein y su petición de perdón televisada. El mes de abril de 2012 supuso una quiebra en la imagen del monarca y un punto de inflexión en el tratamiento de su vida privada en los medios, entre ellos, en Vanity Fair.

En los casi diez años de vida de VFEspaña, como decíamos, la monarquía y la nobleza son dos grandes intereses para la revista. A lo largo de sus primeros ciento cuatro números las intimidades y el trasfondo de las diferentes familias y casas reales del mundo -sobre todo la española- van a ocupar un enorme espacio. Si centramos nuestro interés en el tratamiento de la Casa Real, observamos un crecimiento en la atención dedicada a la monarquía y en el tono crítico con la misma, sobre todo a raíz de los casos Corinna y Nóos. En marzo y noviembre de 2010 logran dos exclusivas: acompañar en secreto a los príncipes de Asturias (Garzón, 2013: 14-16) y contactar con Selina Scott, supuesta amante del rey (que aunque es anunciada como tal, internamente desbarata tal presupuesto). Sin embargo, los reportajes no son más que relatos almibarados sobre la monarquía.

Pero los acontecimientos no se van a precipitar hasta abril de 2012, momento en que el rey se rompe la cadera en Botswana, salta a la palestra zu Sayn-Wittgenstein y el soberano pide perdón por su comportamiento. Es aquí cuando hay una ruptura del aura invulnerable de la monarquía respecto a los medios. En junio de ese año, VFinvestiga sobre Corinna y se encuentra con presiones para que no publiquen la información. El pacto de silencio sobre la corona está más que dañado.

A propósito de eso, Garzón señala, en la carta de ese número, que:

una amiga arquitecta me cuenta que lo único que puede hacerse con el agua para evitar humedades y daños irreparables en las estructuras de los edificios es facilitarles los canales de paso. No hay manera de absorberlo, desviarlo o contenerlo. Ni más solución que conducirlo. Y un buen arquitecto es el que se preocupa también de dibujar 
salidas. [...] Al final, me dice mi amiga con mucha sensatez, lo que no fluye, lo que se retiene, termina por destrozar cualquier estructura por muy sólida que parezca en el plano. Me parece una reflexión muy pertinente para comentar con estos señores en el próximo cafés.

Es decir, que las instituciones, en este caso la monarquía, no deben intentar tapar los escándalos porque, al final, explotan. Vanity Fair, por tanto, se posiciona como el sano canal, el cuarto poder, que permite al Estado funcionar de forma correcta. No están en contra de la Corona, solamente de las malas actuaciones de sus miembros y las denuncian para que no ensucien a la institución.

\section{¿Quién es Corinna zu Sayn-Wittgenstein?}

Con ese espíritu afrontan el reportaje sobre la princesa, realizado por Eva Lamarca, David López y Alberto Pinteño, que es ilustrado con fotos de archivo. La de la portada, está tomada de un evento en Ascot en 2004 y se reproduce también en el interior a modo de imagen de grupo. Se incluye además una, que aparece en el índice y en el interior de ella en la regata Laureus de 2005, en la que el rey entregó los galardones. De ese mismo evento, pero del celebrado en Barcelona en 2006, se recoge otra fotografía: la alemana, al fondo, es precedida por los duques de Palma y don Juan Carlos.

La que abre la pieza la muestra con una jarra de cerveza y con traje tradicional, en el Oktoberfest de Munich -imposible no recordar la foto que acabó con la relación del príncipe Felipe con Eva Sannum- y llama la atención que no sea la portada. También resulta curioso que no presentaran el reportaje con una imagen que juntase a la princesa con el monarca, cuando las hay. Además aparecen otras imágenes de personas que hacen declaraciones para el reportaje y de la princesa con el rey, con lady Alexandra Spencer y con el príncipe Casimir. Igualmente hay una foto de familia antigua de los Sayn-Wittgenstein y de su exprometido. El perfil que nos llega es la de una glamurosa mujer, cercana a los círculos del poder y la nobleza y, naturalmente, vinculada a don Juan Carlos.

Respecto al reportaje, el titular es "Y de repente, Corinna"4 y el subtítulo se pregunta: "¿Quién es Corinna zu Sayn-Wittgenstein? ¿A qué se dedica? ¿Dónde vive? ¿Ha puesto fin don Juan Carlos a su relación con ella para frenar la polémica?" ${ }^{\prime 5}$, señalándose que van a trazar el retrato de la misteriosa princesa alemana con la ayuda de diversas fuentes. La información comienza, precisamente, con una carcajada telefónica del primer marido y padre de la hija mayor de la princesa, Philip J. Adkins, que afirma que estuvo en la cacería junto al rey, su exmujer y el segundo hijo de ella, cuyo padre es el príncipe Casimir zu Sayn-Wittgenstein. El grueso del texto se basa en sus declaraciones puesto que el resto de fuentes, en su mayoría, permanecen en el anonimato.

Pero volviendo a la cacería de abril de 2013 de Botswana, Adkins, asegura que era un viaje de familia y amigos, invitados por el empresario sirio Mohamed Eyad Kayali. Asimismo asegura que era "sobre todo el viaje de dos personas mayores que querían estar en la selva juntos, probablemente por última vez en su

\footnotetext{
${ }^{3}$ Garzón, Lourdes. (2012, Junio, n046). "Un poco de misterio", Vanity Fair, p. 14.

${ }^{4}$ Lamarca, Eva; López, David \& Pinteño, Alberto. (2012, Junio, n46). "Y de Repente Corinna", Vanity Fair, p. 68.

${ }^{5}$ Ibídem.
} 
vida, hablando frente al fuego" ${ }^{\prime \prime}$. A propósito de esto, nos cuenta que fue quien enseñó a Corinna Larsen a cazar en su luna de miel en África, y que por eso fue al viaje: a enseñar la caza al hijo de diez años de la princesa. Sobre la noche del accidente dice que "estaba muy oscuro y era un entorno con el que uno no está [...] el Rey se desorientó" $"$. También asegura que su ex vive asustada porque periodistas de todo el mundo le acusan de ser la amante del rey, aunque él parece no dar ningún valor a esos rumores.

La revista traza una breve biografía de la alemana, que nació en Fráncfort en 1965, domina cinco idiomas y estudió en la Webster University de Ginebra. Hija del responsable ya fallecido de la aerolínea brasileña Varig en Europa, siempre viajó y tuvo buen nivel de vida. De joven trabajó en París y allí conoció a Adkins, en 1989, mudándose con él a Londres. Tras el nacimiento de su hija, su relación se deterioró y terminó. Tras su ruptura, se comprometió con el heredero de Mercedes-Bentz que había dejado a su esposa por ella, pero la relación se rompió sin formalizarla. Entonces conoció al príncipe Casimir zu Sayn-Wittgenstein, que descendía de una antigua familia y se casaron en Londres en enero de 2000, con la oposición de los padres de él.

Poco antes, zu Sayn-Wittgenstein había comenzado a trabajar para la fábrica de armas británica Boss \& Co, que tenía nuevos propietarios desde 1999 y deseaban crear una agencia deportiva para aumentar el negocio. Pusieron como director Gavin Gardiner, de Sotheby's, que explica que ficharon a la alemana porque "tenía estilo y conocía a la gente correcta"8. Su misión consistía, añaden los periodistas, en organizar cacerías y safaris de lujo; de forma que así fue como se adentró en el mundo de los grandes negocios y el ambiente en que conoció al rey, quien la visitó en Londres en 2005.

Uno de los amigos del monarca, cuya identidad se protege, afirma que la relación se remonta, al menos, a febrero de 2004, momento en que la princesa organizó una cacería para don Juan Carlos en Mozambique y que ella se ocupaba de todo y estaba a su lado siempre. También asegura que esas fiestas de caza no eran más que la tapadera de un doble negocio pues empezó cobrando por organizar el evento y, luego, acabó por cerrar ella los tratos. Como el negocio florecía, fichó como ayudante a la hija del duque de Marlborough y su tercera esposa, lady Alexandra Spencer-Churchill, pero la relación acabó mal.

Además, en 2006 dejó Boss \& Co. En noviembre del año anterior había fundado la empresa Apollonia, que según su web, se dedica a relacionar a empresas e instituciones. Su socio, el inglés Richard Frederick Maxwell Cook, que en Panamá tiene una compañía especializada en la gestión de sociedades en paraísos fiscales, rechaza hacer declaraciones. También en 2006, es contratada por la Fundación Laureus, los premios más prestigiosos del mundo del deporte, como directora estratégica de su junta consultiva para buscar grandes empresas patrocinadoras y desfila por la alfombra roja de Barcelona, junto con el presidente de la misma, precedida por el rey y los duques de Palma, como se ve en el reportaje. También se divorcia pocos meses después de casarse, tras tener un hijo, de su segundo marido.

Un amigo del Príncipe, que desea permanecer anónimo, asegura a VFque:

siempre se ha comentado que se casó para obtener un título y un pequeño principito. Como decimos en Londres, es una mujer a la que le encanta subir por la escalera: de

\footnotetext{
${ }^{6}$ Lamarca, Eva; López, David, and Pinteño, Alberto. (2012, Junio, n46). "Y de Repente Corinna", Vanity Fair, p. 68.

7 Ibídem, p. 71.

8 Ibídem, p. 73.
} 
un empresario a un príncipe, después se la relacionó con un duque británico muy importante... ¿Quién será el próximo? ¿Dios? ${ }^{9}$

Aunque su primer esposo desmiente que sea una escaladora social, los rumores son tan fuertes que la alemana autoriza a sus abogados de Schillings, especializados en la protección de reputaciones de individuos de perfil alto, empresas y marcas, a que hablen con Vanity Fair. Y lo que aseguran a la revista es que los que declaran que se casó con Casimir por su posición solo es producto de los celos pues ella ya conocía a todo el mundo. También aseguran que el tipo de relación que mantiene con don Juan Carlos es estrictamente de amistad, sin nada inapropiado, y que por ello no hay más que hablar. Sin embargo, desde la redacción de la revista sí consideran que se puede decir mucho sobre los negocios de la princesa. En febrero de 2006 fue la organizadora de un viaje del rey a Alemania y en abril de ese año, se encarga de la planificación, según la fuente de la revista, del viaje oficial de los Reyes a Arabia Saudí. La empresa del príncipe Al-Waleed, con quien tuvo un encuentro, confirma que fue consejera estratégica de la delegación española. $V F$ recoge la declaración de una fuente anónima de que fue:

punto de partida de una larga negociación que desembocó en enero de 2012 en el contrato por casi 7.000 millones de euros para la construcción del AVE entre las ciudades de Medina y La Meca para el consorcio español liderado por Renfe, Talgo, Adif y las empresas saudíes Alshoula y Al Rosan. El acuerdo más importante alcanzado por la industria española en el extranjero ${ }^{10}$.

Un año después, volvió en representación del rey, según un comunicado de la empresa árabe, para hacer seguimiento del proceso. Sin embargo, la embajada de Arabia Saudí en España dice que fue un viaje a título particular para llevar un mensaje al príncipe de parte del rey. Desde Zarzuela, el portavoz explica que viajó "como representante de una agencia de inversión saudí, que ese es el único desplazamiento oficial en el que ha participado y que 'no consta que haya ninguna relación profesional' con el Rey" 11 .

En paralelo, la revista recoge cómo fuentes del entorno del monarca señalan que, para frenar la polémica, este habría decidido cancelar su relación con la princesa. El cierre del reportaje va acompañado de las declaraciones de los abogados de zu Sayn-Wittgenstein que desmienten que haya misterio en torno a la princesa. Explican que desde 2008 reside en Mónaco y que tiene una segunda residencia en Suiza, donde estudia su hijo; así como que pasa muy poco tiempo en España, lugar en el que no tiene propiedades. También insisten en que su cliente no quiere hablar ni de su vida privada, ni de sus negocios y que tampoco desea publicidad. Desde VFrecuerdan que su primer marido ya había asegurado que su principal cualidad era la lealtad.

Al final de la información, los letrados preguntan que, si pudieran contactar con la esquiva alemana, cuál sería la pregunta más importante que le harían. Los periodistas formulan el gran interrogante que ha motivado el reportaje: ¿qué relación tiene con don Juan Carlos? Como respuesta solo obtienen una

\footnotetext{
${ }^{9}$ Ibídem, p. 74.

${ }^{10}$ Lamarca, Eva; López, David, and Pinteño, Alberto. (2012, Junio, n046). "Y de Repente Corinna", Vanity Fair, p. 77.

${ }^{11}$ Ibídem.
} 
declaración que afirma que es amiga del rey y que no hay ni ha habido una relación inapropiada con él, por lo que despacho y clienta se preguntan por qué habría que añadir nada más.

El misterio de Corinna zu Sayn-Wittgenstein no queda resuelto en el reportaje. El perfil que transmiten las imágenes y las diferentes declaraciones, muchas de ellas sumidas en el anonimato, es el de que hay algo oculto sobre su relación con el rey y de tremenda importancia. Se intuye que no es solamente su amante o su confidente sino que utiliza su posición para lograr privilegios. Las declaraciones de su primer marido para negar los rumores de arribismo y escaladora social no son sino reafirmaciones que al lector le llegan sobre su actitud. El silencio impuesto a su alrededor lo confirma: VFha encontrado no solo a una mujer vinculada de alguna manera con el rey, lo que ya tiene interés de por sí, sino que ha empezado a adentrarse en la cara oculta de don Juan Carlos y la monarquía y, por subsiguiente, también en la del trato de los medios de comunicación con la Corona. De hecho, este número sobre la alemana será el primera de una serie interminable de portadas que va a protagonizar. El escándalo no ha hecho más que comenzar.

\section{Un año después: qué (más) se sabe de Corinna}

Como decíamos, el caso Corinna va a seguir coleando y al año siguiente, en abril de 2013, en Vanity Fair vuelven a centrar su interés en la amiga del rey. Llama la atención que el reportaje no ocupe la portada, siendo esta para Marie Chantal Miller y Olympia de Grecia, en un reportaje sobre princesas modernas vestidas a la moda. Además, Lourdes Garzón, en la carta ${ }^{12}$ introductoria, dice que el número más vendido del año, con diferencia, fue el otro dedicado a zu Sayn-Wittgenstein. También que tuvo considerable repercusión en medios internacionales, pese a que en España pocos se hicieron eco de ello porque el día de la salida a quiosco los reyes aparecieron juntos por primera vez desde hacía meses, en una maniobra propagandística de la Casa Real.

Señala que las cifras de ventas y la difusión del reportaje son prueba del interés de la ciudadanía por el tema, pese a las presiones recibidas para no publicarlo. Y, en esta ocasión, cuentan con declaraciones directas de la alemana. Por ello extraña que no incidan sobre ello en la portada, aunque el índice sí que lo abren con una foto de la princesa bailando vestida de gala, que también aparece a toda página en el interior. A diferencia del otro número, la información sobre la princesa en este es más breve (páginas 74 a 81 ), de las que solo la primera, que únicamente es el titular y un párrafo, y tres más son de texto.

La directora prosigue su carta ${ }^{13}$ diciendo que en el segundo reportaje sobre la amiga del soberano se incide en "cuál es el trabajo de Corinna zu Sayn-Wittgenstein y qué relación tiene con acuerdos que afectan a empresas españoles que se negociaban o se cerraban en viajes oficiales", es decir, "¿qué mediaciones hace nuestro Monarca, en qué asuntos y con qué consecuencias o beneficios?". Además, detalla, que el director del CNI compareció en el Congreso para hablar sobre la princesa y el rey; precisamente la persona que, a propósito del otro número, se preocupaba del reportaje que estaban preparando y quien les hizo llegar repetidamente que no gustaba.

Garzón insiste en que a los lectores sí y añade que una recomendación de ese tipo a un medio de comunicación es una cuestión escandalosa. Por todo ello, vuelven a acercarse a zu Sayn-Wittgenstein. El

\footnotetext{
${ }^{12}$ Garzón, Lourdes. (2013, Abril, n056). "La Pregunta del Millón", Vanity Fair, p. 14.

${ }^{13}$ Ibídem.
} 
reportaje, titulado "Al servicio de Su Majestad", comienza de una forma similar a la de aquella, ya lejana, exclusiva de los Príncipes de Asturias, aunque prosigue críticamente y de una manera muy distinta. El subtítulo reza:

Oficialmente no consta. Nunca ha trabajado para el Gobierno. Es solo una amiga de don Juan Carlos. Pero hoy, un año después del episodio de Botsuana, Corinna zu SaynWittgenstein se ha convertido en un asunto de Estado. David López sigue la pista de la princesa alemana, desde El Pardo a Mónaco, para desvelar sus servicios prestados al Rey (y a España). Desde la organización de la luna de miel de los príncipes hasta sus gestiones con Arabia Saudí y el Kremlin. La otra versión oficial de la conexión española y los negocios de una mujer que asegura ahora vivir amenazada ${ }^{14}$.

En el cuerpo de la información se nos dan más datos sobre la princesa. En 2004, tras acudir el rey a una cacería en Mozambique organizada por ella, recibe del monarca el encargo, en primavera, de preparar la luna de miel de los Príncipes de Asturias, con el beneplácito del heredero. Una fuente anónima que trabajaba con ella afirma que apenas dormía y estaba muy preocupada de que no se filtrase nada.

En Vanity Fair explican que un año después de que el nombre de la princesa alemana saltara a los medios, nadie quiere aparecer en un reportaje relacionado con ella porque es tabú. El motivo es que ha trascendido la crónica rosa y se ha convertido en un asunto de Estado. La versión que se mantiene es que no consta, aunque en las últimas semanas habían trascendido datos sobre su presencia en la casa "La Angorrilla, en el Pardo, perteneciente a Patrimonio Nacional y a disposición de Zarzuela, donde, según algunas informaciones habría vivido. Por sus viajes con el Rey. Y por el supuesto uso de escolta oficial"15. Respecto a la vivienda, fuentes de Zarzuela confirman que ha estado de visita, mientras que los rumores apuntan que ha estado allí cuatro años. Un cazador dice que es muy astuta y sabe acariciar el lomo.

Una persona próxima a su empresa Apollonia afirma que tiene mentalidad estratégica y que su vida discurre entre Mónaco, Londres y Suiza. También su entorno asegura estar muy nerviosos por su seguridad ya que recibe amenazas. Además, la princesa explica a $V F$ que está muy preocupada por las informaciones falsas que circulan sobre ella en España pero que sus contratos de confidencialidad le impiden decir nada y cree que está en peligro.

Es un momento en que el foco de atención se ha intensificado sobre ella por los correos entregados por Diego Torres, exsocio de Urdangarin, al juez Castro en medio del Caso Nóos que desvelan que acudió a la primera conferencia del Instituto y que la amistad con el rey se consolidaba. La luna de miel de los príncipes había sido un éxito y logró que el vasco presidiera la Fundación en España, aunque él lo rechazó. Pese a no tener nada que ver con el caso investigado, temió ser llamada a declarar y habló públicamente, sin consultarlo con el monarca y, tras no ser defendida ni por Urdangarin ni por Zarzuela. Según una amiga, don Juan Carlos le envió un mensaje diciendo que la había "leído y que la apoyaba"16.

En 2004, igual que Nóos despegaba, lo hacía la vida personal y profesional de la princesa. Ese año conoció al rey y empezó a hacer negocios con oligarcas rusos establecidos en Londres, lo que permitió que, en un

\footnotetext{
${ }^{14}$ López, David. (2013, Abril, n056). "Al servicio de Su Majestad", Vanity Fair, p. 74.

${ }^{15}$ Ibídem, p. 77.

${ }^{16}$ Ibídem, p. 78.
} 
momento tenso de las relaciones bilaterales entre España y Rusia, colaborase para que Putin recibiera al Rey en el Kremlin en junio de 2005 en un viaje privado. En febrero de 2006, el ruso realizó su primera visita de Estado a España.

Ese mismo año, don Juan Carlos visitó Boss \& Co, haciendo ella de anfitriona. Poco después, dejó la empresa y borró todos sus rastros, llevándose la foto del rey y contratando a un informático para limpiar su ordenador. También se cuenta que organizó el viaje al estado de Baden-Württemberg del monarca y en el que se desplazó a Arabia Saudí. Sobre este, según un miembro del Ejecutivo de Zapatero, se "escuchaban comentarios sobre si existía una señora. Pero en la parte sentimental, no profesional"17 y quita importancia a sus supuestas gestiones.

Aunque VFintenta ponerse en contacto con Moratinos, que viajaba en el avión con los reyes, el ministro de Industria y nueve empresarios españoles, rechaza hacer declaraciones. La alemana también fue con ellos pero, según Zarzuela, como enviada de la agencia de inversión saudí SAGIA. Sin embargo, la revista averigua que no trabajaba allí y uno de los empresarios asegura que participó en el acuerdo de cooperación entre ambos países (del que saldría en enero de 2012 la firma del proyecto para construir el tren de alta velocidad a La Meca). Pero no fue un caso único, la princesa habría participado en una decena de ocasiones en proyectos ligados al Gobierno.

Aunque los políticos lo niegan, la revista afirma que sí recibió ciertas misiones, sobre todo con Zapatero, pero también en la de Rajoy; siendo la última ocasión a finales de 2012. La princesa confirma a VFque ha cortado todos sus vínculos profesionales con nuestro país y una fuente de Zarzuela dice que se ha roto también la amistad, por lo que sus entrevistas son "desde el rencor"18. No obstante, una amiga suya dice que lo hace por miedo, por el Caso Nóos y las amenazas recibidas, pues aunque don Juan Carlos le ha dicho que no se preocupe, ella "sabe que a ciertos niveles hay cosas que están por encima de la amistad"19.

La imagen transmitida respecto a zu Sayn-Wittgenstein es mucho más inquietante que en el otro reportaje pues se ha sabido más y más de su relación con el rey y se ha pasado de considerarla su amante a ser una figura conflictiva para la monarquía y el Estado. Especialmente, en el contexto de los casos de corrupción y los escándalos que han salpicado a la monarquía. No se trata únicamente del perfil de una escaladora social sino del de una mujer en las cloacas del poder del país, que hace cuestionar el papel de la monarquía y del Gobierno y hasta qué punto hay agujeros negros que la ciudadanía desconoce. Don Juan Carlos es el introductor de la princesa en ese juego de negocios y política estatal y su papel es examinado desde un punto de vista más crítico que en el anterior reportaje. Respecto al tratamiento fotográfico, vuelve a haber fotos de archivo que insisten en su glamour y en cómo usa su atractivo para acercarse a los poderosos, entre ellos, al rey.

\section{Conclusiones}

La hipótesis de este trabajo es que la Corona ha gozado del favor de los medios de comunicación desde la Transición pero que, paulatinamente, diversos escándalos relacionados con la Familia Real han contribuido a que el silencio y la simpatía con que se han tratado sus informaciones se hayan erosionado. Prueba de

\footnotetext{
17 Ibídem, p. 81.

${ }^{18}$ López, David. (2013, Abril, n056). "Al servicio de Su Majestad", Vanity Fair, p. 81.

${ }^{19}$ Ibídem.
} 
ello son los dos reportajes dedicados por Vanity Fair a Corinna zu Sayn-Wittgenstein en junio de 2012 y abril de 2013, y al comportamiento y actitudes de don Juan Carlos, así como el papel de la monarquía en España. Como dice Lourdes Garzón en la carta de la directora del segundo número sobre la alemana: "¿no les gustaría saber qué mediaciones hace nuestro Monarca, en qué asuntos y con qué consecuencias o beneficios?"20.

Tras el análisis de los números, concluimos que la investigación sobre la princesa es, en primer lugar y ante todo, un trabajo de búsqueda y cuestionamiento de la monarquía. No en clave republicana (al contrario, VF se dibuja a sí mismo como un medio monárquico), sino un intento de trazar una nueva relación entre los medios de comunicación y la Casa Real en España. Si iniciaron su trayectoria con la entrevista a la mediática Rania de Jordania y siguieron logrando una exclusiva, muy amable, con los príncipes de Asturias, el devenir de la publicación se sitúa criticando e investigando dentro de la monarquía española, especialmente a Urdangarin y también a la infanta Cristina y a don Juan Carlos.

Pero no con el objetivo de dinamitar la institución y acabar con su prestigio, al contrario. Garzón plantea su revista, y por extensión el periodismo, un canal por el que debe fluir lo relacionado con las instituciones democráticas. Como señala en la carta del primer número dedicado a la princesa Corinna, utilizando una metáfora:

lo único que puede hacerse con el agua para evitar humedades y daños irreparables en las estructuras de los edificios es facilitarles los canales de paso. No hay manera de absorberlo, desviarlo o contenerlo. Ni más solución que conducirlo. $\mathrm{Y}$ un buen arquitecto es el que se preocupa también de dibujar salidas. [...] lo que no fluye, lo que se retiene, termina por destrozar cualquier estructura por muy sólida que parezca en el plano ${ }^{21}$.

Es decir, que la forma de garantizar la pervivencia de la institución es precisamente con la adscripción de esta a la política informativa normal de la democracia: en la que todo está bajo la mirada del periodismo, que actúa como cuarto poder o contrapoder. Así, en vez de dañar a la Casa Real, lo que se consigue es integrarla en una verdadera democracia y darle un papel en la sociedad democrática que actualmente no ha tenido al estar protegida por los medios. Eso, en buena medida, también ha contribuido a los excesos de los miembros de la Familia Real que se sentían invulnerables y libres de actuar como deseaban, al contar con las simpatías de la prensa. Quizá el no estar tan seguros de su inmunidad hubiera parado escándalos como el del Caso Nóos mucho antes.

En lo relativo a la imagen de la monarquía que traslada $V F$ en estos reportajes, se puede decir que no es negativa aunque sí es inquietante: no consideran que la institución sea inmune a las investigaciones de sus periodistas y reprende a los intentos de la Casa Real por controlar lo que publican, acusándoles de antidemocráticos. La línea editorial es monárquica y especialmente favorable a los entonces príncipes de Asturias, don Felipe y doña Letizia. El rey, incluso en estos dos reportajes, no queda mal retratado. Su presencia simplemente revolotea sobre la misteriosa zu Sayn-Wittgenstein. Que en ninguna de las portadas

${ }^{20}$ Garzón, Lourdes. (2013, Abril, n056). "La Pregunta del Millón", Vanity Fair, p. 14.
${ }^{21}$ Garzón, Lourdes. (2012, Junio, n046). "Un poco de misterio", Vanity Fair, p. 14. 
se le presente, pese a haber fotos que se publican en el interior, junto a la alemana, no deja de ser un cuidadoso trato respecto del soberano por parte de la revista.

La princesa Corinna es la que peor imagen transmite: tanto secretismo, incluso pese a contar con benéficas declaraciones de por ejemplo su exmarido, transmite al lector que tiene mucho que ocultar (lo tenga o no). En el segundo número, de junio de 2013, la revista logra contactar con la propia amiga del rey, pero sin fotos. La implicación que ha aparecido en los medios vinculando su persona al Caso Nóos ha hecho que haya cambiado su postura respecto a aparecer en la prensa. Desde la publicación dicen que es astuta, inteligente, práctica y más atractiva en persona. $\mathrm{E}$ inciden en que hay mucho sobre su vida y sus negocios que inquieta en el país. El silencio que ha estado manteniendo ya no le favorece y aunque se rumorea que su relación con el monarca sigue igual que antes, lo cierto es que su caso ha despertado tal repercusión que está desprotegida porque la dimensión adquirida por su persona ha traspasado lo que la Casa Real y el Gobierno puede controlar. Está, como dice una fuente cercana a ella, por encima de lo que la amistad obliga. Los medios de comunicación se han impuesto a la política informativa que la monarquía española venía manteniendo $y$, en concreto, $V F$, que por otra parte no esconde su línea editorial proclive a la monarquía. Estamos pues, en conclusión, en un nuevo escenario entre la Casa Real y los medios, de corte mucho más progresista ya que considera que la transparencia es la única forma que tiene la monarquía de sobrevivir, especialmente al producirse la abdicación de Juan Carlos I y la sucesión por parte de Felipe VI.

\section{Bibliografía}

Carratalá, A. (2015). El tratamiento de la Monarquía española en las viñetas de los medios digitales. Revista Dígitos, (1), 127-154.

Castro-Villacañas, J. (2013). El fracaso de la Monarquía (Vol. 33). España: Grupo Planeta (GBS).

Domínguez, M., \& Mateu, A. (2014). Are the winds of change blowing in Spain? Cartoonists' critical analysis of King Juan Carlos' elephant-hunting trip. Journalism Studies, 15(2), 187-203.

Eyre, P. (2012). La soledad de la reina: Sofía: una vida. España: La Esfera de los Libros.

Fernández, F. R. (2013). El "tabú" periodístico de la monarquía en España. La crisis real y la crisis coyuntural. Revista latina de comunicación social, (68), 217.

Garzón, L. (2013). Vanity Fair. Lo que nunca se ha contado de las mejores exclusivas. España: Planeta.

González Requena, J. (1996). El texto tres registros y una dimensión. Trama y fondo: revista de cultura, 1, 3-32.

Herrero, J. C., \& Medina, J. P. M. (2016). El perdón como estrategia de restauración de la imagen: el caso del rey Juan Carlos. ZER-Revista de Estudios de Comunicación, 21(40).

Lamet, P. M. (2012). Yo te absue/vo, Majestad. España: Grupo Planeta Spain.

López García, G., \& Valera Ordaz, L. (2013). La información sobre la Monarquía española en los nuevos medios digitales: Eldiario. es y Vozpopuli. Com. Adcomunica, num. 6, 65-81.

Marfil Medina, J. P. and Pérez Herrero, J. C. (2016). El discurso del perdón en comunicación política: la disculpa de Juan Carlos I. Opción, 32.

Medina, J. P. M., \& Herrero, J. C. P. (2016). El discurso del perdón en comunicación política: la disculpa de Juan Carlos I. Opción, 32(7). 
Mogin-Martin, R. (2006). La monarquía española según la revista" El Jueves": análisis de la antología "Tocando los Borbones". In Humor y política en el mundo hispánico contemporáneo (pp. 115-132).

Morton, A. (2013). Ladies of Spain: Sofía, Elena, Cristina y Letizia: entre el deber y el amor. España: La Esfera de los Libros.

Müller, J. (2014). Felipe VI y la nueva generación de españoles. Mensaje, 63(630), 12-14.

Palacios Bañuelos, L. (2015). La monarquía española del "juancarlismo" a Felipe VI. La Albolafia: Revista de Humanidades y Cultura, 5, 191-208.

Pablos Coello, J. M., \& Ardévol Abreu, A. (2009). Prensa española y monarquía: el «silencio crítico» se termina. Estudio de caso. Anàlisi: quaderns de comunicació i cultura, (39), 237-253.

Peñafiel, J. (2011). El rey no abdica. España: La Esfera de los Libros.

Ramos, F. (2012). Los escándalos de la corona española en la prensa digital y el futuro de la monarquía de la amnesia y el silencio cómplice al tratamiento exhaustivo los medios. Razón y palabra, 17(79).

Ramos, R. (2013). O Rei de Espanha foi caçar elefantes: a construção discursiva do evento nos media portugueses. Cadernos de Linguagem e Sociedade, 14(1), 17-40.

Rorty, R. (1990). El Giro Lingüístico, Dificultades metafilósoficas de la filosofía lingüística. España: Paidós. Sintes Olivella, M., Yeste Piquer, E., Franch Puig, P. (2016). La sucesión de Juan Carlos I por Felipe VI. Análisis de contenido de los artículos editoriales publicados por los diarios de Madrid y de Barcelona. Estudios del Mensaje Periodístico, 22(2).

Urbano, P. (1997). La Reina. España: Plaza \& Janés Editores.

Urbano, P. (2008). La Reina muy de cerca. España: Booket.

Urbano, P. (2011). El precio del trono. España: Grupo Planeta Spain.

Vilallonga, J. L., \& de España, J. C. I. R. (1993). El rey: conversaciones con D. Juan Carlos I de Borbón. España: Plaza \& Janés.

Widlak, E., \& Sorribes, C. P. (2015). "Annus horribilis" y su impacto en la imagen de la monarquía española. La Reina Sofía en los diarios El País y El Mundo (2012-2014). Estudios sobre el Mensaje Periodístico, 21(1), 207.

Zugasti, R. (2005). La legitimidad franquista de la Monarquía de Juan Carlos I: un ejercicio de amnesia periodística durante la transición española. Comunicación y sociedad. vol. XVIII, núm.2, p.141-168.

Zugasti, R. (2007). La forja de una complicidad: monarquía y prensa en la transición española (1975-1978). Madrid: Fragua. 